\title{
Пространственный анализ как инструмент изучения журналистов: к постановке вопроса
}

\author{
Егор Жаровский
}

В статье рассматриваются возможности и перспективы использования пространственного анализа в современных исследованиях журналистов. Автор предпринимает попытку раскрыть теоретикометодологические основания этой методической процедуры, выделить основные направления в ее осмыслении и определить области применения для изучения работников СМИ.

Обзор ряда концепций

и эмпирических исследований указывает

как на высокую продуктивность пространственного анализа в изучении журналистов,

так и на разнообразие взглядов относительно его применения в медиаисследованиях.

Ключевые слова: пространственный анализ, профессиональный журналист, медиаисследования, СМИ, журналистика.
@ Жаровский Егор Романович аспирант кафедры социологии массовых коммуникаций факультета журналистики МГУ имени М.В. Ломоносова (г. Москва, Россия), egor.heat@mail.ru

\section{Введение}

Функционирование и развитие современного медиапространства практически невозможно представить без его главной движущей силы - профессиональных журналистов. Так, благодаря непрерывной работе сотрудников СМИ читатели, зрители и слушатели оперативно получают сведения об окружающей действительности, рекламодатели регулярно распространяют информацию о собственных товарах и услугах, а органы государственного управления и политические партии оказывают влияние на общественное мнение.

Выполняя свои обязанности, каждый журналист оказывается вовлеченным в сложную систему экономических и административно-управленческих отношений внутри редакции, выступает субъектом права в рамках законодательства о СМИ, может принимать участие в политическом процессе, обладает возможностью воздействовать на массовое сознание аудитории. Многоаспектность журналистской деятельности и многоликость связанной с ней проблематики порождают необходимость в применении различных дисциплинарных подходов при изучении работников СМИ.

В настоящее время профессиональное сообщество журналистов рассматривается с позиций социологии журналистики (Фомичева, 2012), медиаэкономики (Свитич, 
Смирнова, Вырковский, 2015), медиаменеджмента (Вырковский, 2016), права СМИ (Панкеев, Тимофеев, 2018), психологии журналистики (Пронин, Пронина, 2013), филологии (Маркова, Рацибурская, Иссерс, Мельник и др., 2017), культурологии (Малеина, 2015), истории (Игумнов, 2014), а также политической науки (Окара, 2014). Отдельные аспекты, связанные с выделением предельно обобщенных черт журналистской работы, попадают в поле зрения философов (Батаева, 2013; Линде, 2015). Исследователи могут также одновременно использовать сразу несколько из перечисленных выше подходов (Третьякова, 2013) или комбинировать их (Вакурова, 2012) при проведении исследования журналистов и их работы в СМИ. В результате изучение журналистов сегодня носит явно междисциплинарный характер, что представляется вполне закономерным в силу появления новых требований к выполнению журналистской работы и, соответственно, иных профессиональных задач и практик.

Стоит отметить, что обилие применяемых в исследованиях СМИ и журналистики подходов уже дает возможность детально охарактеризовать практически все стороны журналистской деятельности на современном этапе ее развития. В то же время условия «окружающей среды» (особенности места, где находится редакция СМИ), в которых журналистам приходится работать, нередко рассматриваются фрагментарным образом или отодвигаются на второй план.

Так, изучая печатные издания республик Северного Кавказа в контексте этнической культуры, Р.П. Овсепян (2007) среди факторов влияния на местную прессу называет важные аспекты: процесс глобализации, усиление национального самосознания, повышение межэтнической толерантности. Вместе с тем более конкретные социокультурные условия, которые также могут оказывать воздействие на СМИ (к примеру, национальный состав населения республик, действующие в них общественные организации и учреждения культуры, исторические этапы развития той или иной редакции), исследователем уже не затрагиваются. При обращении к международному проекту Journalism in Change. Professional Journalistic Cultures in Poland, Russia and Sweden хотелось бы отметить сосредоточенность исследователей на условиях труда в редакциях СМИ трех стран, на взаимоотношениях журналистов с обществом, политических препятствиях в их работе, уровне свободы и этических представлениях (Nygren, Dobek-Ostrowska (eds.), 2015). Тем не менее рассмотрению их социально-экономических, политических и историко-культурных особенностей, которые являются основополагающими условиями реализации журналистской деятельности, здесь отводится скромное место.

В связи с этим, на наш взгляд, в качестве инструмента, изначально ориентирующего исследователя на изучение территориальной специфики журналистики, может быть предложен пространственный анализ. Его использование позволяет не только выявить сходства и различия между профессиональной деятельностью журналистов, работающих в пределах разных территорий, но и в перспективе определить закономерности функционирования редакций средств массовой информации, связанные с их местоположением.

Учитывая заметные отличия между журналистикой отдельных стран и регионов, что неоднократно подтверждалось компаративными исследованиями последних десятилетий (Засурский, Колесник, Свитич, Ширяева, 1998; Hallin, Manchini, 2004; Weaver, Willnat (eds.), 2012), пространственный анализ может оказаться довольно продуктивным для исследований СМИ и журналистов. В частности, необходимость понимания условий и особенностей работы журналистов в различных городах и регионах России, а также потребность 
в получении зарубежного опыта актуализирует внимание к нему.

Нами предпринимается попытка развернуть дискуссию вокруг пространственного анализа применительно к изучению журналистов и в общих чертах раскрыть его теоретико-методологическое содержание. В качестве объекта исследования мы рассматриваем пространственный анализ как особую методическую процедуру, а предмета - возможности его применения в исследованиях работников СМИ.

\section{Исследование журналистов в ракурсе географической науки: концептуальные рамки}

Изучая специфику пространственного анализа в исследованиях СМИ и журналистики, нужно сначала определиться с объектом и предметом географии как системы научного знания, являющейся его методологическим истоком. Фундаментальным концептом, исходя из которого географы выделяют объекты для проведения своих исследований, является географическая оболочка. На сегодняшний день под ней в отечественной ${ }^{1}$ и зарубежной науке (Messerli, Rey, 2012) понимается целостная часть планеты Земля, представляющая собой среду деятельности человека и состоящая из семи взаимодействующих сфер - литосферы (земной коры), атмосферы (воздуха), гидросферы (воды), педосферы (почвы), биосферы (живых организмов), социосферы (общества) и техносферы (искусственных технических сооружений). Предметом же географии выступает структура, функционирование, развитие представленных выше сфер и взаимосвязи между ними.

Поскольку журналистика представляет собой общественный, а не природный феномен, то журналисты и их профессиональная деятельность относятся к двум последним из перечисленных выше сфер социосфере и техносфере. Соответственно, и изучение журналистов сквозь призму пространственного анализа целесообразно проводить в контексте социально-экономической географии, для которой общество и его развитие в пространстве является непосредственным объектом изучения (Зубаревич, 2010).

Далее необходимо рассмотреть категории, без обращения к которым использование пространственного анализа как особой познавательной процедуры лишается смысла. К ним можно отнести термины «географическое пространство» и «территория».

Так, категория «географическое пространство» является производной от понятия «пространство», под которым в самом общем смысле понимается «способ существования объективного мира, неразрывно связанный со временем»². Объективный мир для исследователя-географа представлен реально существующими объектами, процессами, явлениями Вселенной, расположенными в пределах планеты Земля и подверженным изменениям с течением времени. В результате географическое пространство трактуется как трехмерная часть Вселенной, которая ограничена географической оболочкой и разделена на территории ${ }^{3}$.

В свою очередь, территория как структурная единица географического пространства представляет собой участок земной поверхности, обладающий конкретными границами и географическими координатами (широтой и долготой). Общепринятая типология территорий в географической науке отсутствует, однако актуальная исследовательская практика в России и за рубежом обозначает следующие территориальные уровни: глобальный, континентальный, национальный, региональный и локальный, а также промежуточные ступени между ними (субконтинентальные, субнациональные, субрегиональные). Каждый из этих уровней связан с определенными типами территорий различной размерно- 
Таблица 1. Территориальные уровни в географических исследованиях

\begin{tabular}{|c|l|l|}
\hline № & \multicolumn{1}{|c|}{$\begin{array}{c}\text { Территориальный } \\
\text { уровень }\end{array}$} & \multicolumn{1}{|c|}{ Тип территории (примеры) } \\
\hline 1 & Глобальный & Мир в целом \\
\hline 2 & Континентальный & Северная Америка, Евразия, Африка \\
\hline 3 & Субконтинентальный & $\begin{array}{l}\text { Страны Юго-Восточной Азии, Латинской Америки, } \\
\text { Северной Африки }\end{array}$ \\
\hline 4 & Национальный & Россия, Китай, США \\
\hline 5 & Субнациональный & Дальневосточный, Центральный, Южный федеральные округа \\
\hline 6 & Региональный & $\begin{array}{l}\text { Московская область, штат Пенсильвания, } \\
\text { Внутренняя Монголия }\end{array}$ \\
\hline 7 & Субрегиональный & $\begin{array}{l}\text { Южный берег Крыма, северные районы Московской области, } \\
\text { черноморское побережье Краснодарского края }\end{array}$ \\
\hline 8 & Локальный & Москва, Лондон, Париж \\
\hline
\end{tabular}

сти (см. табл. 1). Журналисты могут быть изучены в контексте любого из указанных территориальных уровней.

Сам пространственный анализ в широком смысле представляет собой изучение картографических изображений, на которых визуализированы данные по свойствам определенных объектов, явлений или процессов в зависимости от их размещения (местоположения) в географическом пространстве (Тикунов (ред.), 2010). Углубляясь в методику пространственного анализа, можно выделить три основных этапа в его процедуре: 1) ввод и обработка исходных данных в геоинформационной системе (ГИС); 2) анализ распределения изучаемых объектов и проявления их характеристик в различных точках географического пространства; 3) процесс создания карт для визуализации, полученных в ходе анализа результатов.

По итогам первого этапа исследователь получает массив данных с присвоенными для каждого изучаемого объекта географическими координатами, а по окончании второго - результаты анализа или моделирования свойств объекта, предназначенные для проектирования картографических изображений (третий этап). На основании готовых карт (или картосхем) исследователь способен сформулировать выводы об особенностях изучаемого объекта в пределах конкретной территории. Найдя свое изначальное применение в географии, пространственный анализ как познавательная процедура с каждым годом становится значимее в научных направлениях социально-гуманитарного цикла, получив уже достаточно широкое распространение в исследовательской практике среди историков (Акашева, 2011), экономистов (Макар, 2012) и лингвистов (Левина, 2016).

Аналогичным образом пространственный анализ может быть применен и при изучении профессиональной деятельности работников СМИ. Исходными данными, к примеру, могут послужить результаты опроса журналистов, контент-анализа их публикаций, сведения о редакции, в которой они работают. Наиболее простым способом с точки зрения технической реализуемости является импорт данных о журналистах, занесенных в таблицы в Excel, в доступное для использования программное обеспечение (ArcGIS, MapInfo, GeoMedia и др.). Диапазон операций, которые могут быть выполнены на стадии анализа в ГИС, весьма широк: анализ сетей, зонирование, картометрическое измерение, простран- 
Таблица 2. Возможности использования ГИС при изучении журналистов

\begin{tabular}{|c|c|c|c|c|}
\hline № & $\begin{array}{c}\text { Тип исходных данных } \\
\text { (примеры) }\end{array}$ & $\begin{array}{l}\text { Oперация } \\
\text { в ГИС }\end{array}$ & $\begin{array}{l}\text { Функция } \\
\text { операции }\end{array}$ & $\begin{array}{c}\text { Визуализированные } \\
\text { на карте явления }\end{array}$ \\
\hline 1 & $\begin{array}{l}\text { Результаты опроса } \\
\text { журналистов из одного } \\
\text { города, посвященного } \\
\text { сотрудничеству редакций } \\
\text { СМИ между собой }\end{array}$ & Анализ сетей & $\begin{array}{l}\text { Определение } \\
\text { свойств сети } \\
\text { и наиболее } \\
\text { коротких путей } \\
\text { между ее } \\
\text { элементами }\end{array}$ & $\begin{array}{l}\text { Территории } \\
\text { с низкой или } \\
\text { высокой } \\
\text { плотностью связей } \\
\text { между редакциями } \\
\text { сМи }\end{array}$ \\
\hline 2 & $\begin{array}{l}\text { Результаты опроса } \\
\text { российских журналистов } \\
\text { из разных регионов, } \\
\text { посвященного их } \\
\text { политическим } \\
\text { предпочтениям во время } \\
\text { избирательной кампании }\end{array}$ & Зонирование & $\begin{array}{l}\text { Группировка } \\
\text { объектов по } \\
\text { определенному } \\
\text { признаку или } \\
\text { отношению } \\
\text { к другим } \\
\text { объектам }\end{array}$ & $\begin{array}{l}\text { Территории } \\
\text { с преобладанием } \\
\text { журналистов, } \\
\text { голосующих } \\
\text { за «Единую Россию», } \\
\text { КПРФ, ЛДПР, } \\
\text { «Справедливую } \\
\text { Россию» и т.д. }\end{array}$ \\
\hline 3 & $\begin{array}{l}\text { Географические } \\
\text { координаты адресов } \\
\text { редакций СМИ } \\
\text { и бесплатных } \\
\text { парковочных мест }\end{array}$ & $\begin{array}{l}\text { Картометрическое } \\
\text { измерение }\end{array}$ & $\begin{array}{l}\text { Расчет } \\
\text { расстояния } \\
\text { между } \\
\text { объектами } \\
\text { в пространстве }\end{array}$ & $\begin{array}{l}\text { Измеренные } \\
\text { расстояния } \\
\text { от редакций } \\
\text { до парковок } \\
\text { с возможностью } \\
\text { построения } \\
\text { кратчайшего } \\
\text { маршрута }\end{array}$ \\
\hline
\end{tabular}

ственное моделирование, сетевая оптимизация данных. Все это открывает новые горизонты для изучения журналистской деятельности (см. табл. 2).

В то же время среди некоторых особенностей территории, которым уделяется существенное внимание в социально-экономической географии, можно обозначить отраслевую структуру и функции экономики, характер территориального разделения труда, черты расселения, историю развития и пространственную конфигурацию населенного пункта, половозрастной, этнический и конфессиональный состав населения, его менталитет, культурную и политическую идентичность. Совокупность этих условий составляет внередакционную среду, в которую в большей или меньшей степени погружены все работники СМИ конкретной территории (населенного пункта, региона, страны). При применении пространственного анализа для изучения журналистов ее также необходимо учитывать.
Стоит отметить, что перечисленные выше примеры далеко не полностью охватывают поле медиаисследований, которое потенциально может оказаться в фокусе внимания ученого, опирающегося на пространственный анализ. Вероятно, при последующем изучении журналистов и их профессиональной деятельности в перспективе могут быть найдены и другие возможности применения данного подхода.

\section{Пространственный анализ в изучении работников СМИ на эмпирическом уровне}

Современная практика эмпирических исследований демонстрирует, что изучение журналистской деятельности зачастую сопряжено с пространственным анализом. Среди подобных исследований в первую очередь можно назвать массовые опросы сотрудников СМИ разных стран, регионов и городов. Например, при осуществлении международного исследовательского проекта Worlds of Journalism в 2012-2016 гг. бы- 
ли опрошены профессиональные журналисты из 67 стран мира. По результатам составлены портреты профессиональных журналистов, включающие сведения об их социально-демографических характеристиках, типе занятости, этических представлениях, принципах профессиональной работы. Поскольку данные были получены для каждой из этих стран по отдельности, то можно говорить об исследовании работников СМИ на национальном уровне.

Другим примером из актуальной практики изучения журналистов является исследовательский проект «Газеты малых и средних городов России в 2010-х гг.», в рамках которого был проведен опрос журналистов из 26 субъектов РФ и, в частности, зафиксированы предпочтения журналистов в выборе темы своего материала, степень их свободы, а также финансовое благополучие редакций, в которых они работают (Свитич, Смирнова, Ширяева, Шкондин, 2015). Таким образом, речь здесь идет уже об изучении журналистов на региональном уровне.

Оба представленных выше примера свидетельствуют о том, что исследователи СМИ в настоящее время склонны к применению пространственного анализа - характеристике журналистов и специфики их работы в пределах разных стран и регионов. Однако его реализация носит неполный характер, поскольку полученные данные не обработаны в ГИС и не переведены в формат картографических изображений.

Отметим, что наиболее успешно данную задачу удалось реализовать составителям картосхем, посвященных свободе СМИ и журналистов. На картосхеме, размещенной на сайте проекта Media Freedom, наглядно представлены преобладающие в разных странах профессиональные ориентации журналистов (этатизм, либерализм, патриотизм и др.), а на картографическом изображении проекта Reporters Without Borders очаги ущемления свободы журналистов (страны с наименьшим индексом свободы печати). Обе картосхемы позволяют изучить на визуальном уровне состояние журналистской деятельности на глобальном уровне и, соответственно, оценить перспективы взаимодействия журналистов из разных стран мира.

Отметим, что авторы подобных проектов пока прямо не указывают на применение пространственного анализа как методической процедуры несмотря на ее фактическое использование. Однако условия для более широкого распространения пространственного анализа в исследованиях журналистов уже сформированы.

\section{Поворот к пространственному анализу в теоретическом осмыслении журналистики}

Попытки рассмотрения журналистики и массовой коммуникации в контексте географической науки с ориентацией на пространственный анализ предпринимаются уже достаточно давно. Еще в 1985 г. была издана коллективная монография «География, медиа и популярная культура» (Burges, Gold (eds.)), в которой британские и американские исследователи рассматривают медиа с позиций социальноэкономической географии. Авторам этой книги удается сопоставить особенности телевещания на Ямайке, в США и Великобритании, определить локализацию мест освещения событий в американских газетах за 1839-1969 гг., сравнить роль СМИ в формировании чувства страха у жителей города и сельской местности.

С развитием и повсеместным распространением Интернета в 1990 гг. появляется и новое проблемное поле, открытое для применения пространственного анализа. Так, ирландский исследователь (Kitchin, 1998) рассматривает киберпространство, состоящее из Интернета и интранетов (частных корпоративных сетей), в качестве нового объекта для географи- 
ческого анализа и картографирования. Год спустя американские исследователи (Crang M., Crang P., May (eds.), 1999.) призывают обратиться к изучению взаимосвязей между информационно-коммуникационными технологиями (ИКТ) и объектами туризма, ставшими, по их мнению, неотьемлемой частью виртуального пространства. В результате к концу 1990 гг. в парадигме зарубежных медиаисследований, связанных с изучением Интернета, закрепляется понятие «пространство».

В 2000 гг. понимание пространства в области исследований журналистики продолжает меняться. В научный обиход постепенно вводится понятие «медиапространство». В течение первой половины 2000 гг. зарубежные исследователи пытаются обозначить концептуальные рамки данного понятия через описание СМИ и журналистики различных стран. Так, в 2002 г. в США издается монография «Медийные миры. Антропология на новой местности», в которой проводится культурологический анализ продукции СМИ и киноиндустрии разных территорий, основанный на выявлении специфических черт этнической культуры местных жителей (Ginsburg, AbuLughod, Larkin (eds.), 2002). В поле зрения американских исследователей попали такие объекты, как Египет, Индия, Таиланд, Белиз, Казахстан, Боливия, Нигерия, Замбия, Тибет, г. Шанхай, о. Бали. В этот же период появляются и работы, в которых подробно рассматриваются теоретико-методологические основания понятия «медиапространство». В частности, предпринимаются попытки определить структуру и разновидности медийного пространства, а также его место в повседневной жизни людей (Couldry, McCarthy (eds.), 2004).

Во второй половине 2000 гг. исследователи уже прямо заявляют о необходимости разработки нового направления в изучении журналистики, связанного с анализом пространственных аспектов ее функцио- нирования. Эксперты (Falkheimer, Jansson (eds.) , 2006) отмечают, что средства массовой коммуникации (и взаимосвязи между ними) уже являются неотемлемым компонентом материального и символического пространства территорий по всему миру, а потому для их описания и анализа требуется специальная научная дисциплина география коммуникаций. В то же время П. Адамс (2009) утверждает, что СМИ как объект изучения давно привлекают внимание географов, однако из-за отсутствия единого понимания методологии исследований журналистики с ракурса географической науки их усилия носят неорганизованный и эпизодический характер. По мнению американского исследователя, теория журналистики и массовой коммуникации нуждается в разработке концепции, позволяющей связать воедино компоненты медиапространства (журналистов, редакцию СМИ и техническую инфраструктуру) и географического пространства (территории - страны, регионы, города).

С середины 2000 гг. эстафету, связанную с теоретическим осмыслением понятия «медиапространство», принимают и отечественные исследователи. Однако в отличие от своих зарубежных коллег российские ученые видят концептуальные истоки данного термина не в географии, а в социологии. Согласно Е.Н. Юдиной (2005: 39), медиапространство - это «часть социального пространства, организующая социальные практики и представления агентов, включенных в систему производства и потребления массовой информации». Несколько иное, но настолько же далекое от географии, определение медиапространству дает Л.Б. Зубанова (2008: 6), понимая под ним «зону реальных и потенциальных контактов каждого из участников коммуникации, определяемой оценочными (ценностными) установками адресата». Аналогичного мнения придерживается и О.В. Монастырева (2010: 61), для которой медиапро- 
странство - «социально конструируемое понимание мира».

На протяжении 2010 гг. возможности применения пространственного анализа в медиаисследованиях осмысляются с новых позиций, однако сущностное понимание данного вопроса остается прежним. В рамках зарубежных исследований создаются предпосылки для возникновения нового научного направления - медиагеографии. В 2014 г. в США издается коллективный научный труд, посвященный накопившимся за предыдущие десятилетия теоретическим наработкам и актуальным проблемам медиагеографии (Adams, Craine, Dittmer (eds.), 2014). В книге последовательно рассматриваются история развития и современное состояние отраслевых разделов медиагеографии (географии радио, Интернета, фотографии, фильмов, видеоигр), а также предпринимается анализ различных медийных пространств - пространства печатного слова, опосредованного звука, телекоммуникации, медийного капитала и самовыражения.

В российских же исследованиях наблюдается фрагментация взглядов, относящихся к возможностям использования географического подхода в изучении журналистики. Часть отечественных исследователей продолжила разработку концепции медиапространства в русле социологической науки (Дзялошинский, 2012; Ним, 2013; Николаева, Котляр, 2016). Исследователи-географы не выделяют медийное пространство в виде отдельного концепта, а косвенно упоминают его наряду с социальным и культурным пространством (Замятин, 2010; Замятина, 2012).

Некоторые исследователи пытаются осмыслить зарубежные представления о медиагеографии и предложить собственное видение этой научной дисциплины. Так, М.М. Янгляева, Т.С. Якова и М.В. Захарова (2016) в качестве объекта медиагеографии называют «информационные, культурные, политические и технологические процессы, формирующие "пространственные неясности" как сущностные признаки глобализации», а предмета - «взаимосвязи медиа и пространства», которые проявляются в особенностях развития и функционирования медиасистем разных стран и регионов.

Таким образом, представленные выше концепции свидетельствуют о том, что пространственный анализ привлекает к себе довольно высокое внимание со стороны теоретиков, изучающих СМИ и журналистику. Тем не менее в сфере медиаисследований существует еще немало отраслевых направлений, не получивших должного теоретического осмысления в контексте этой методической процедуры. Одним из них является изучение профессиональных журналистов и их работы в СМИ.

\section{Заключение}

По итогам концептуализации пространственного анализа и обзора возможностей его применения в изучении профессиональных журналистов можно сформулировать следующие выводы.

Во-первых, пространственный анализ широко представлен в исследованиях журналистики. На это, в частности, указывают уже проведенные отечественные и зарубежные эмпирические исследования работников СМИ в контексте глобального, национального и регионального территориальных уровней. Параллельно осуществляется и осмысление медиаисследований с точки зрения географии, что также свидетельствует об усилении внимания к данному вопросу.

В то же время наблюдается заметный разброс мнений и взглядов на перспективы изучения журналистики при помощи пространственного анализа. Одни исследователи предлагают сконцентрировать внимание на понятии «медиаспространство», другие ученые тяготеют к анализу национальных или региональных медиасистем, 
некоторые эксперты пытаются определить территориальную специфику журналистской работы через медиаконтент, передающийся в местных СМИ. Отсутствие единой общепризнанной интерпретации для этой познавательной процедуры несомненно затрудняет ее вхождение в парадигму исследований СМИ и журналистики.

Во-вторых, пространственный анализ как методическая процедура, применяемая при изучении работников СМИ, реализуется не совсем полно как исследователями журналистики, так и представителями географической науки. Так, географы в большинстве случаев ограничиваются довольно обобщенными объектами для проведения пространственного анали- за - населением территории, отраслями экономики, видами транспорта и т.п. В результате отдельные профессиональные общности (в нашем случае журналисты) их интересуют в редких случаях. Исследователям СМИ, как правило, достаточно просто указать территорию, в пределах которой они будут изучать журналистов. Как следствие, необходимость в построении картографических изображений и изучении по ним характеристик не возникает. Поэтому успешное внедрение пространственного анализа в сфере изучения журналистов во многом будет зависеть и от практики междисциплинарного изучения журналистов, совмещающего в себе специфику медиаисследований и географии.

\section{Примечания}

${ }^{1}$ Исследовательский проект Worlds of Journalism. Режим доступа: https://www. worldsofjournalism.org (дата обращения: 13.11.2019).

2 Исследовательский проект Media Freedom. Режим доступа: http:// mappingmediafreedom.de/ (дата обращения: 13.11.2019).

з Международный неправительственный проект Reporters Without Borders. Режим доступа: https://rsf.org/en/ranking (дата обращения: 13.11.2019).

\section{Библиография}

Акашева А.А. Пространственный анализ данных в исторических науках. Применение геоинформационных технологий. Н. Новгород: Нижегородск. гос. ун-т, 2011.

Батаева Е.В. Символология и герменевтика медиа-образа // Вестн. Моск. ун-та. Сер. 7: Философия. 2013. № 5. С. 55-66.

Вакурова Н.В. Миссия журналистики как социально-психологический феномен // Вестн. Гос. ун-та управления. 2012. № 9. С. 250-255.

Вырковский А.В. Редакционный менеджмент в печатных и онлайновых массмедиа: процессный подход. М.: МедиаМир, 2016.

Геоинформатика: в 2 кн. / под ред. В.С. Тикунова. М.: Академия, 2010.

Дзялошинский И.М. Коммуникационные стратегии социальных институтов в медиапространстве России: автореф. дис. ... д-ра филол. наук. М., 2012.

Замятин Д.Н. Гуманитарная география: пространство, воображение и взаимодействие современных гуманитарных наук // Социологическое обозрение. 2010. Т. 9. № 3. С. 26-50.

Замятина Н.Ю. Территориальные идентичности и социальные структуры // Общественные науки и современность. 2012. № 5. С. 151-163. 
Засурский Я.Н., Колесник С.Г., Свитич Л.Г., Ширяева А.А. Журналист: российско-американские социологические исследования. М.: Эслан, 1998.

Зубанова Л.Б. Современное медиапространство: подходы к пониманию и принципы интерпретации // Вестн. Челябинск. гос. акад. культуры и искусств. 2008. № 2 (14). С. 6-17.

Зубаревич Н.В. Регионы России: неравенство, кризис, модернизация. М.: Независимый ин-т соц. политики, 2010.

Игумнов Д.А. Критика идей и деятельности русских либералов в материалах журнала «Прямой путь» (1909-1914) // Вестн. Моск. ун-та. Сер. 8: История. 2014. № 4. С. 93-101.

Левина М.3. Лингвистическая география как основа ареальных исследований мордовских языков // Финно-угорский мир. 2016. № 3. С. 50-59.

Линде А.Н. Подход Ю. Хабермаса к теоретическому изучению политической коммуникации // Вестн. Моск. ун-та. Сер.7: Философия. 2015. №5. С. 91-104.

Макар С.В. Пространственный анализ: развитие концепции и возможностей применения // Вестн. Финанс. ун-та. 2012. № 2 (68). С. 61-72.

Малеина Е.А. Культурология медиапространства (интеграция традиционных СМИ и Интернета) // Ярославск. пед. вестн. 2015. № 5. С. 366-371.

Маркова Е.М., Рацибурская Л.В., Иссерс О.С., Мельник Ю.А. и др. Роль СМИ в демократизации и креативизации современного русского языка (круглый стол) // Вестн. Моск. гос. обл. ун-та (эл. журн.). 2017. № 1. Режим доступа: https://evestnik-mgou.ru/79/ Articles/Doc/799 (дата обращения: 13.11.2019).

Монастырева О.В. Медиапространство: обзор представлений и подходов к пониманию // Вестн. АмГУ. 2010. Вып. 50. С. 56-62.

Николаева Е.М., Котляр П.С. Медиапространственная коммуникация: проблема аксиологических ориентаций // Вестн. Бурятск. гос. ун-та. Сер.: Педагогика. Филология. Философия. 2016. Вып. 3. С. 30-38.

Ним Е.Г. Медиапространство: основные направления исследований // Бизнес. Общество. Власть. 2013. № 14. С. 31-41.

Овсепян Р.П. Многонациональная пресса республик Северного Кавказа в этнокультурном процессе // Изв. Южного фед. ун-та. Сер.: Филологические науки. 2007. № 1-2. C. 261-268.

Окара А.Н. «Четвертая власть» между обществом и государством (политические журналисты как часть политического современной России) // Полития: Анализ. Хроника. Прогноз. 2014. № 3 (74). С. 57-74.

Панкеев И.А., Тимофеев А.А. Правовое поле массмедиа: тренды последних лет // МедиаАльманах. 2018. № 2. С. 27-34.

Пронин Е.И., Пронина Е.Е. Медиапсихология: новейшие информационные технологии и феномен человека // Общественные науки и современность. 2013. № 2. С. 151-161.

Свитич Л.Г., Смирнова О.В., Вырковский А.В. Экономическое положение редакций (по результатам опроса редакторов и журналистов газет средних и малых городов России) // Вестн. Моск. ун-та. Сер.10: Журналистика. 2015. № 3. С. 46-65.

Свитич Л.Г., Смирнова О.В., Ширяева А.А., Шкондин М.В. Газеты средних и малых городов России в 2010-х гг. (результаты опроса редакторов и журналистов). М.: Фак. журн. МГУ, 2015. 
Третьякова О.В. Политическая и правовая культура общества и журналистика // История, философия, политика и юридические науки, культурология и искусствоведение. 2013. № 8-2 (34). С. 185-190.

Фомичева И.Д. СМИ среди средств социальной коммуникации // Вестн. Моск. ун-та. Сер. 10: Журналистика. 2012. № 1. С. 60-71.

Юдина Е.Н. Медиапространство как культурная и социальная система. М.: Прометей, 2005.

Янгляева М.М., Якова Т.С., Захарова М.В. Внешнеполитическая коммуникация и медиагеография: взаимосвязь и взаимозависимость // Медиаскоп. 2016. Вып. 4. Режим доступа: http://www.mediascope.ru/2232

Adams P., Craine J., Dittmer J. (eds.) (2014) The Ashgate Research Companion to Media Geography. Burlington, Vermont: Ashgate Publishing.

Adams P. (2009) Geographies of Media and Communication. Hoboken, New Jersey: Wiley-Blackwell.

Burges J., Gold J.R. (eds.) (1985) Geography, the Media and Popular Culture. London: Groom Helm.

Couldry N., McCarthy A. (eds.) (2004) Mediaspace: Place, Scale and Culture in a Media Age. New York: Routledge.

Crang M., Crang P., May J. (eds.) (1999) Virtual Geographies: Bodies, Space and Relations. New York: Routledge.

Falkheimer J., Jansson A. (eds.) (2006) Geographies of Communication: The Spatial Turn in Media Studies. Göteborg: Nordicom.

Ginsburg, F.D., Abu-Lughod L. and Larkin B. (eds.) (2002) Media Worlds: Anthropology on New Terrain. Berkeley, CA: University of California Press.

Hallin D., Manchini P. (2004) Comparing Media Systems: Three Models of Media and Politics. Cambridge, UK: Cambridge University Press.

Kitchin R. (1998) Towards geographies of cyberspace. Progress in Human Geography 22 (3): 385-406.

Messerli P., Rey L. (2012) Integrating physical and human geography in the context of mountain development: the Bernese approach. Geographica Helvetica 67 (1-2): 38-42.

Nygren G., Dobek-Ostrowska B. (eds.) (2015) Journalism in change. Journalistic culture in Poland, Russia and Sweden. Pieterlen and Bern: Peter Lang.

Weaver D.H., Willnat L. (eds.) (2012) The Global Journalist in the 21st Century. New York: Routledge. 